\title{
Longitudinal respiratory survey of shipyard workers: effects of trade and atopic status
}

\author{
D J Chinn, I C Stevenson, J E Cotes
}

\begin{abstract}
A respiratory sample survey of 609 shipyard workers was conducted in 1979: the men were reassessed an average of $7 \cdot 2$ years later. The 53 deaths between the surveys were related to age, level of lung function and smoking but not to trade as a welder or caulker/burner. Of the survivors, $488(88 \%)$ were seen, including 425 men who had retired or been made redundant. Redundancy was related to age, smoking, and respiratory symptoms; the average reduction in duration of employment per symptom was 0.44 years. Changes in respiratory symptoms included onset of chronic bronchitis and wheeze on most days (numbers respectively 77 and 109) and increased breathlessness on exertion $(n=89)$; significant related factors included smoking, previous metal fume fever or pneumonia, and, for breathlessness, trade as a welder or caulker/burner. Electrocardiographic evidence for myocardial ischaemia was also associated with increased breathlessness. The annual declines in FEV 1 and other spirometric indices were related to age, to being a smoker at the time of the initial survey, and to trade as a welder or caulker/burner compared with trades that did not involve welding or burning. There was significant interaction between these effects. In a subsample of 124 redundant workers there was also significant interaction between the effects of fumes and atopy (skin test positive to common antigens) or a raised serum $I_{g} E$ concentration. It was concluded that welding fumes interacted with smoking and an atopic constitution to cause respiratory impairment. The results related mainly to exposures in the past and were not necessarily relevant for present day conditions in the industry.
\end{abstract}

Division of Environmental and Occupational Medicine, Medical School, Newcastle upon Tyne and Royal Infirmary, Sunderland

D J Chinn, I C Stevenson, J E Cotes
In 1979 a cross sectional respiratory survey was carried out on a stratified sample of shipyard workers in north east England. ${ }^{1}$ The sample included all the welders and caulker/burners aged 45 or over who were still working in the shipyard, half those under this age, those who had left within the previous nine years, and a $5 \%$ sample of other tradesmen. The men exhibited a high prevalence of respiratory symptoms which, in the case of chronic productive cough and undue breathlessness on exertion, were related to both current smoking and the proportion of time spent working in confined spaces as a welder or caulker/burner. The forced expiratory volume $\left(F E V_{1}\right)$ and other indices of airflow limitation were reduced in relation to the fume exposure among welders and caulker/burners who had ever smoked. No similar association was observed in the nonsmokers. The findings were evidence for fumes from welding and caulker/burning interacting with tobacco smoke to damage the lungs of shipyard workers. For most lung function indices the impairment associated with exposure to fumes was related to age. This suggested that the adverse effect of fumes might have been due to work in unfavourable conditions in the past before the need was recognised for exhaust ventilation. If this was so then the result of the cross sectional study did not reflect the effects of present day working conditions. In addition, an effect of fumes in non-smokers might have been missed because the number of such men was small, especially in the older age groups. These deficiencies would be less for a follow up study on account of its greater sensitivity due to subjects acting as their own controls. Such a study has now been undertaken with both repetition of the initial measurements and inclusion of additional ones relating to atopic status. The latter might influence susceptibility to the effects of fumes.

\section{Methods}

For the initial cross sectional study in 1979 , the men were approached through, and most were seen at, the shipyard for completion of an occupational and respiratory questionnaire, measurement of stature, and spirometry. Results were analysed for 607 men. In 1980 a subsample was drawn comprising all the men with wheeze on most days, undue breathlessness 
on exertion, or a reduced $\mathrm{FEV}_{1}(\leqq 1.64$ SD below predicted), or a combination of these, together with a control group matched for age and trade. In all, 233 men $(80 \%)$ were seen. On the subsample the original observations were repeated, skin prick tests were carried out, and measurements made of total lung capacity and its subdivisions, transfer factor, and the physiological response to exercise. For the follow up study, the men were to have been approached through the shipyard, but most were found to have been made redundant or to have taken early retirement. Some had retired on attaining age 65 . An attempt was made to see all these men at their homes; they were then invited to a local centre (centre A) where the survey procedures were to be repeated and additional measurements made as for the subsample. Some men not seen at this time were seen subsequently at centre $B$. Men still working had the survey procedures carried out at the shipyard. Those in the subsample also performed the additional measurements. The causes of death of men who had died between the surveys was obtained from the death certificates.

The MRC questionnaire of respiratory symptoms was completed in 1979, in 1980, and at follow up. ${ }^{2}$ The occurrence of cough with phlegm on most days for as much as three months in the year was considered evidence for chronic bronchitis (MRC); undue breathlessness on exertion was when a man could not keep up with one his own age on level ground (breathlessness grade 3 or above). These symptoms, also wheeze on most days, were analysed individually. They also contributed equally to the symptom score which had the limits zero when there were no material symptoms and three when all were present. The occupational questionnaire in 1979 was detailed and was used to construct an exposure score for welding or burning in confined spaces. This was based on the reported duration of each job in years and the proportion of time spent in confined spaces (graded 1-3). The intensity of exposure was the sum of the product of duration and time for each job divided by the total years of employment. At follow up the subsequent employment history was recorded. Atopic status in men who attended for additional tests was established by prick testing with four common allergens (house dust mite, cat fur, aspergillus fumigatus, and mixed pollen). A positive reaction was a weal of larger diameter than that to the control solution. Blood was drawn for estimation of serum IgE concentration by the Phadebas Prist method (Pharmacia). Electrocardiographic evidence of myocardial ischaemia was sought in men on whom it was proposed to perform an exercise test.

Ventilatory capacity was measured using a dry bellows spirometer (McDermott) by one of six trained operators. Before each measurement session the spirometer was calibrated with a standard orifice and weight. The subjects were seated and performed the measurement a minimum of five times. In 1979 the first two blows were rejected and the highest values for forced expiratory volume $\left(\mathrm{FEV}_{1}\right)$ and forced vital capacity (FVC) were taken from the next three technically satisfactory results; these blows were recorded digitally using a Sony 2 channel tape recorder. At follow up all five blows were recorded. The output from the spirometer, in the form of digital volume per $10 \mathrm{~ms}$ time increment was analysed using a Hewlett Packard 9825 computer and printer. Peak expiratory flow rate (PEF) was the highest flow averaged over ten time increments. The forced expiratory flow rates, including PEF and the flow rates when $50 \%$ and $25 \%$ of vital capacity remained to be expired $\left(\mathrm{MEF}_{50 \%} \mathrm{FVC}\right.$, and $\mathrm{MEF}_{25 \%}$ FVC), were the best individual results for curves that met the criteria of the European Coal and Steel Community. ${ }^{3}$ The measurements were repeated about $\mathbf{4 0}$ minutes after an inhalation of salbutamol; an increase in $\mathrm{FEV}_{1}$ of more than or equal to $10 \%$ (calculated as $200\left(x_{2}-x_{1}\right) /\left(x_{2}+x_{1}\right)$ ) was taken as evidence for a bronchodilator response.

Total lung capacity was measured by closed circuit spirometry with helium as the indicator gas: carbon dioxide was absorbed and oxygen added to maintain a constant resting respiratory level during the rebreathing. The test continued until the helium concentration over 30 seconds did not alter by more than $0.02 \%$. Transfer factor was measured in duplicate by the single breath carbon monoxide method using a gas mixture containing $0.28 \%$ carbon monoxide and $14 \%$ helium in air. The breathholding time (about 10 seconds) was calculated using the convention of Jones and Meade, and the alveolar volume was the sum of the volume inspired plus the residual volume obtained independently by closed circuit spirometry. In 1980 and at follow up a resparameter and transfer test apparatus (Morgan) were used respectively. The same operator performed the measurements on both occasions.

Progressive exercise was performed on a cycle ergometer at a pedal frequency of 50-60 a minute. In 1980 the increments of work were $30 \mathrm{~W}$ every three minutes and the endpoint was the symptom limited maximum. At follow up the increments were $12.5 \mathrm{~W}$ each minute and the endpoint was a respiratory exchange ratio of unity. Ventilation was measured using a vane anemometer and cardiac frequency using an electrocardiograph recording from chest leads in the CM5 configuration. ${ }^{4}$ Expired gas was sampled distal to a gas mixing chamber, dried, and analysed for carbon dioxide and oxygen respectively by infrared and paramagnetic gas analysers. Results were analysed on line using a microprocessor (Morgan). Graphs relating ventilation and cardiac frequency to oxygen uptake were prepared from the results for each half minute of exercise and used to 
obtain by interpolation the ventilation and cardiac frequency at an oxygen uptake of $45 \mathrm{mmol} / \mathrm{min}$ $\left(\dot{\mathrm{V}}_{\mathrm{E}} 45\right.$ and $\mathrm{f}_{\mathrm{C}} 45$ respectively). Tidal volume was similarly obtained at a minute volume of $301 / \mathrm{min}$ $(\mathrm{V}, 30)$. The methods have been described elsewhere. ${ }^{5}$

\section{Analysis}

The results for each lung function test on both surveys were scrutinised for their technical quality and only those results that met the selection criteria were included in the analysis. This process led to the rejection of 26 results for PEF and 30 results for $\mathrm{MEF}_{50 \% \mathrm{Fvc}}$. Differences between observers were found to be unimportant. $\mathrm{FEV}_{1}$ measured at home was on average slightly larger than that obtained in the laboratory (mean values respectively 2.681 and $2.641, p<0.01$ ) and the increase following salbutamol was less (mean changes respectively $4.8 \%$ and $8.1 \%, p<0.01$ ). Where both results were available those for the laboratory were used in the analysis. Age was recorded in decimal years.

The analysis was carried out using an IBM 370 computer, the statistical package for the Social Sciences $\left(\right.$ SPSS $\left.^{x}\right)$ of the University of Michigan ${ }^{6}$ and BMDP statistical software. ${ }^{7}$ The procedures included multiple and logistic regression analysis and analysis of variance. The former analyses were performed using a forward stepwise method, the independent variable giving the largest reduction in the residual sum of squares being selected first. The results of the logistic regression analysis were reported in terms of the odds ratio compared with unity which implied no contribution from the variable in question. The $95 \%$ confidence intervals were rounded off downwards to one place of decimals, and the $5 \%$ level of probability was accepted as significant. Tack welders who traditionally included both former riveters and others who were in poor health from any cause were excluded from analyses of the effects of trade as a welder or caulker/burner compared with other trades. Men from other trades were also excluded from analyses which considered the effects of intensity of exposure to fumes before 1979 or duration of exposure to fumes after 1979.

Men who answered yes to the question: "Have you ever had bronchial asthma?" were excluded from analyses which addressed the role of atopic status. Table 1 gives the numbers of subjects used for the different comparisons. Further information is given in the results. The dependent variables which were categorical (yes/no) included death during the period of follow up (compared with survival), the acquisition or loss of respiratory symptoms, a change in smoking category (in each instance compared with no change), atopy, and a serum $\mathrm{I}_{g} \mathrm{E}$ concentration in excess of $250 \mathrm{IU}\left(\mathrm{I}_{8} \mathrm{E} 250\right)$. The continuous dependent variables were the changes in indices of lung function, the IgE concentration expressed on linear and logarithmic scales and, for men made redundant, the time in years to redundancy. The changes in lung function per year at follow up-that is $\left(L F_{2}-L F_{1}\right) \div\left(t_{2}-t_{1}\right)$-were expressed in absolute units and as percentages of the mean lung function (LF) over the period of follow up (where $\left.(\mathrm{LF})=0 \cdot 5\left(\mathrm{LF}_{1}+\mathrm{LF}_{2}\right)\right) \cdot{ }^{8}$ Allowance for stature was made by dividing the change in lung function by the square or the cube of the stature. ${ }^{910}$ The independent variable age was the mean over the period of follow up; it was expressed as age, age ${ }^{3}$ and age St. ${ }^{311}$ The level of lung function was expressed in absolute units and also in standard deviation units about the reference values ${ }^{12}$; the latter were nearly independent of age. The reference values were those reported previously ${ }^{5}$ or in the case of flow volume indices the values for asymptomatic industrial workers assessed using the present methods.

Preliminary analysis with allowance made for age showed that the absolute decline in lung function was independent of age $\mathrm{e}^{3}$ and the explained variance was not increased by the use of terms that included stature. IgE concentration explained more of the variance when expressed on a linear than on a logarithmic scale.

The use of the percentage instead of the absolute decline in lung function led to more of the variance being explained, but the contribution attributable to trade as a welder or caulker/burner was rather less than when the absolute decline was used; this was also the case when the mean lung function in standard deviation units was included among the independent variables. With respect to smoking history the current smokers and men who discontinued smoking between the surveys exhibited similar declines in lung function; the declines were greater than for non-smokers and men who were ex-smokers in 1979. Accordingly, the smoking status used in the analysis was that recorded in 1979 .

\section{Results}

A total of 609 men were identified as having participated in the 1979 survey, including two whose

Table 1 Numbers of subjects at follow up (numbers for analyses that included atopic status are in parentheses,

\begin{tabular}{lcc}
\hline Dead & & 53 \\
Not reassessed: lost & 18 & \\
$\quad$ Refused & 48 & 68 \\
$\quad$ III & 2 & 68 \\
Reassessed; included in analysis: & $286(76)$ & \\
$\quad$ Welders & $100(28)$ & \\
$\quad$ Caulker burners & $64(20)$ & $450^{\star}(124)$ \\
$\quad$ Other tradesmen & 37 & \\
Reassessed: results not analysed: & 1 & 38 \\
$\quad$ Tack welders & & 609 \\
$\quad$ Trade not recorded & & \\
Total & \\
\hline
\end{tabular}

^For main analyses. Numbers for analyses of detailed lung function included total lung capacity 145 (55), transfer factor 125 (49), and exercise ventilation 96 (38). 
results were overlooked at the time of the previous analysis; table 1 gives details of their status at follow up. The follow up rate among the living was $88 \%$.

\section{THE LAPSES}

Compared with the participants the men who subsequently became lapses reported a lower average exposure to welding fumes at their initial assessment in 1979 (mean scores respectively 2.12 and 1.89 units) but in all other respects, including age, trade, prevalence of respiratory symptoms, and lung function, the two groups appeared similar (table 2).

\section{THE DEAD}

The men who had died were on average older and smaller than the survivors. At initial assessment they smoked more, had a higher prevalence of productive cough, wheeze, and undue breathlessness on exertion, and reduced lung function compared with the reference value for age and stature (table 2). The risk of dying between the surveys was related to age and lung function; after allowing for these variables the respiratory symptoms did not improve the description of risk. The risk was also unrelated to blood pressure, body mass/stature, ${ }^{2}$ trade, selection for and participation in the 1980 subsample study, and intensity of fume exposure up to 1979 .

The commonest causes of death were cardiovascular diseases and lung cancer where the rate among the welders and caulker/burners was 2.4 per 1000 a year; this did not differ significantly from that for the other tradesmen among whom there was a materially lower proportion of smokers. Six men were reported as having died from respiratory causes other than lung cancer; of these, four had chronic bronchitis with airflow obstruction, one had advanced emphysema, and one recurrent pneumonia without respiratory impairment.

\section{OTHER SELECTION FACTORS}

The participants in the follow up study included 425 men $(87 \%)$ who had left the shipyard since the first survey. In 100 of them the reason given was redundancy but 174 men $(41 \%)$ considered ill health to have contributed. The men who left were older and had more respiratory symptoms in 1979 than those who remained. After allowing for age, a man with a respiratory symptom score of three discontinued working on average 1.32 years (16 months) earlier than a man who was asymptomatic. Smokers were significantly more likely to have discontinued work than non-smokers of the same age, but trade as a welder or burner, and, within the latter trades, the intensity of previous fume exposure, appeared not to be a factor in discontinuing work. Men who were initially seen at home and then volunteered and attended for the additional measurements at centre $A$ were on average five years older and had inferior lung function compared with those who chose not to attend (mean $\mathrm{FEV}_{1}$ in SD units respectively -0.66 $\mathrm{SD}-0 \cdot 21 \mathrm{SD})$.

\section{THE PARTICIPANTS}

The mean age of the participants in 1979 was 45.5 years and at follow up was 52.6 years. Over this period the prevalence of respiratory symptoms on average increased, the proportion of smokers decreased, and the lung function deteriorated (table 2).

\section{CHANGES IN RESPIRATORY SYMPTOMS}

Chronic bronchitis developed between the surveys in 77 men. The risk of bronchitis was increased by being a smoker in 1979 (odds ratio $2 \cdot 0,95 \%$ limits 1.1-3.5). It was unrelated to trade or, among welders and burners, to the proportion of working time between the surveys during which the man was

Table 2 Summary of findings for the participants, the dead, and those who refused or were lost to follow up. (Results for the two men who were ill at the time of follow up have not been included) (SD units in parentheses)

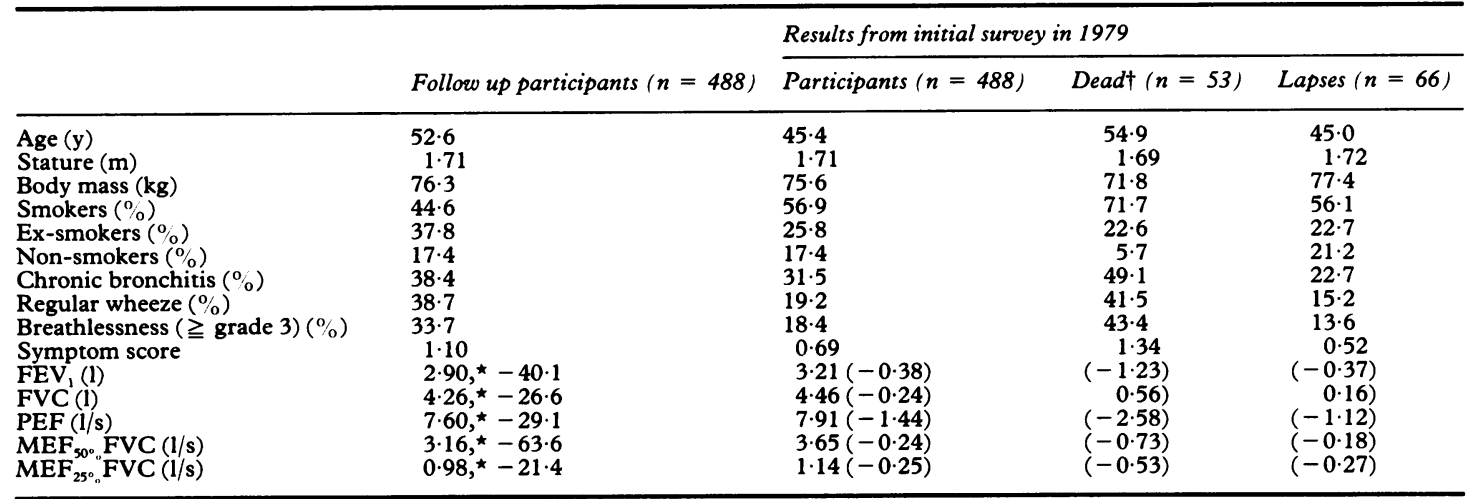

*Indicates change per year $\times 10^{3}$

†Results for all indices except body mass and percentage of ex-smokers significantly different from those for participants. 
Table 3 Factors associated with changes in respiratory symptoms and other features

\begin{tabular}{|c|c|c|c|}
\hline Feature & Categorical variables wit & ratio (E $95 \%$ limits) & $\begin{array}{l}\text { Continuous variables } \\
\text { (direction of association) }\end{array}$ \\
\hline $\begin{array}{l}\text { Chronic bronchitis: } \\
\text { Improved } \\
\text { Developed }\end{array}$ & $\begin{array}{l}\text { Abandoning smoking } \\
\text { Continuing to smoke }\end{array}$ & $\begin{array}{l}4 \cdot 3(1 \cdot 2-14 \cdot 7) \\
2 \cdot 0(1 \cdot 1-3 \cdot 5)\end{array}$ & $\operatorname{Age}(-), F_{1}(+)$ \\
\hline $\begin{array}{l}\text { Wheeze most days: } \\
\text { Improved } \\
\text { Developed }\end{array}$ & $\begin{array}{l}\text { No metal fume fever } \\
\text { Previous pneumonia }\end{array}$ & $\begin{array}{l}3 \cdot 2(1 \cdot 0-9 \cdot 8) \\
2 \cdot 1(1 \cdot 0-4 \cdot 0)\end{array}$ & $\begin{array}{l}\text { Age }(-) \\
\text { Age }(+), \mathrm{FEV}_{1}(-), \text { weight gain }(+)\end{array}$ \\
\hline $\begin{array}{l}\text { Breathlessness: } \\
\text { Improved } \\
\text { Worse } \\
\text { Redundancy } \\
\text { Death }\end{array}$ & $\begin{array}{l}\text { Trade as welder } \\
\text { Previous pneumoniat } \ddagger \\
\text { Continuing to smoke }\end{array}$ & $\begin{array}{l}2 \cdot 8(1 \cdot 1-7 \cdot 0) \\
2 \cdot 0(1 \cdot 2-3 \cdot 5) \\
2 \cdot 1(1 \cdot 1-4 \cdot 0)\end{array}$ & 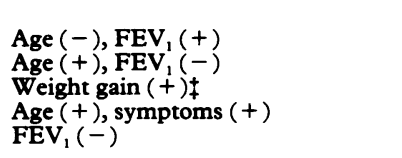 \\
\hline
\end{tabular}

*Among welders and caulker burners.

+Term not significant in presence of $\mathrm{FEV}_{1}$

$\ddagger$ Also in subsample ECG evidence for cardiac ischaemia.

exposed to fumes. Forty four men had chronic bronchitis in 1979 but not at follow up. The chances of recovering from chronic bronchitis were increased by discontinuing smoking between the surveys (odds ratio $4 \cdot 3,95 \%$ limits $1 \cdot 2-14 \cdot 7$ ), by having an above average $\mathrm{FEV}_{1}$ relative to the reference value, and among the welders and caulker/burners by being of below average age. The changes were unrelated to recent exposure to fumes. Wheeze on most days developed in 109 men. The risk of regular wheeze was related to age, a low FEV 1 with respect to the reference value in 1979, and an increase in body mass between the surveys. Among the welders and caulker/burners when $\mathrm{FEV}_{1}$ was omitted from the analysis, a history of pneumonia was then a significant risk factor (odds ratio $2 \cdot 1,95 \%$ limits $1 \cdot 0$ 4.0 ). Twenty two men reported regular wheeze in 1979 but not at follow up. The chances of recovering from wheeze were inversely related to age; not having had metal fume fever was also a good prognostic feature (odds ratio $3 \cdot 2,95 \%$ limits $1 \cdot 0-9 \cdot 8$ ). Changes in the symptom of wheeze were unrelated to smoking or trade and among the welders and burners unrelated to exposure to fumes. An increase in grade of breathlessness between the surveys was reported by $89 \mathrm{men}$. The risk of becoming more breathless was related to age, a low $\mathrm{FEV}_{1}$ with respect to the reference value, weight gain between the surveys, and to trade as a welder or burner (odds ratio $2 \cdot 8$, $95 \%$ limits 1-1-7.0). In the absence of $\mathrm{FEV}_{1}$ a history of pneumonia was also a risk factor (odds ratio $2 \cdot 0$, $95 \%$ limits 1.2-3.5). An increase in breathlessness was associated with a reduced duration of work subsequent to the 1979 survey. Among the subsample, electrocardiographic evidence of cardiac ischaemia was an additional risk factor (odds ratio $2 \cdot 2,95 \%$ limits $1 \cdot 1-4 \cdot 5)$.

Seventeen men reduced their grade of breathlessness between the surveys. The chances of improvement were related directly to $\mathrm{FEV}_{1}$ relative to the reference value and inversely to age. Among the subsample, the men who reported less breathlessness exhibited a below average increase between surveys in the ventilation during submaximal exercise.

Seventy two men discontinued smoking between the surveys. Their decision to do this was a function of age but was apparently independent of respiratory symptoms: 16 ex-smokers resumed smoking between the surveys. The factors that were observed to contribute to changes in respiratory symptoms and other features are summarised in table 3.

\section{ATOPIC STATUS}

Among 98 men in the subsample who attended in 1980 and at follow up 24 were skin test positive to common allergens on both occasions. Three subjects became skin test positive over the period of follow up: none who was initially positive lost reactivity.

At follow up, atopic status and serum IgE concentration ([IgE]) (table 4) were available for 124 welders, caulker/burners, and other tradesmen, among whom 33 were skin test positive: atopy and [IgE] were correlated. [IgE] was related to smoking for men whose atopic status was recorded both at follow up and in 1980 but not for the whole group. After allowing for age and stature, $\mathrm{FEV}_{1}$ and $\mathrm{FEV}_{1} /$ FVC were related to [IgE] and to IgE 250 in the smokers, as defined, but not the non-smokers.

\section{CHANGES IN LUNG FUNCTION}

As the lung function of the welders and caulker/ burners did not differ with respect to any of the

Table 4 Distribution of IgE concentrations

\begin{tabular}{lc}
\hline Concentration (IU) & No \\
\hline$<50$ & 65 \\
$50-149$ & 30 \\
$150-249$ & 11 \\
$250-349$ & 4 \\
$\geqslant 350$ & 14 \\
\hline
\end{tabular}


Table 5 Summary of results at follow up for the 487 men whose trade was recorded (in one man it was not recorded)

\begin{tabular}{|c|c|c|c|c|}
\hline & $\begin{array}{l}\text { Welders } \\
(n=286)\end{array}$ & $\begin{array}{l}\text { Caulker/burners } \\
(n=100)\end{array}$ & $\begin{array}{l}\text { Tack welders } \\
(n=37)\end{array}$ & $\begin{array}{l}\text { Other trades } \\
(n=64)\end{array}$ \\
\hline 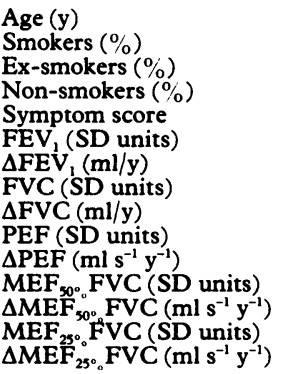 & $\begin{array}{r}53.0 \\
43.0 \\
42.7 \\
14.3 \\
1.16 \\
-0.54 \\
-43.91 \\
0.17 \\
-28.60 \\
-1.34 \\
-34.54 \\
-0.30 \\
-74.03 \\
-0.12 \\
-25.89\end{array}$ & $\begin{array}{r}51.9 \\
47.5 \\
31.3 \\
21.2 \\
1.23 \\
-0.59 \\
-38 \cdot 67 \\
0.11 \\
-32.08 \\
-1.72 \\
-40 \cdot 14 \\
-0.37 \\
-51 \cdot 29 \\
-0.15 \\
-15.61\end{array}$ & $\begin{array}{r}58 \cdot 3 \\
64.9 \\
24.3 \\
10 \cdot 8 \\
1.22 \\
-0.67 \\
-48 \cdot 87 \\
0.08 \\
-35.92 \\
-1.85 \\
-56.53 \\
-0.44 \\
-63.40 \\
-0.12 \\
-15.31\end{array}$ & $\begin{array}{r}48.1 \\
35.9 \\
35.9 \\
28.1 \\
0.56 \\
-0.01 \\
-20.96 \\
0.65 \\
-4.13 \\
-0.92 \\
28.41 \\
-0.08 \\
-39.49 \\
0.09 \\
-14.55\end{array}$ \\
\hline
\end{tabular}

features listed in table 2 their results were combined for the analysis of changes in lung function. Compared with these men the tack welders were on average older with a higher proportion of smokers but similar lung function (table 5 ).

The annual decline in the spirographic indices was in all instances related to age; after allowing for age, for all indices except $\mathrm{MEF}_{25 \%} \mathrm{Fvc}$, the decline was on average greater in current and recent ex-smokers compared with the non-smokers and long term exsmokers. The effect of smoking could be represented as increasing the effect of age but the additional variance explained by this interactive model as compared with the simple additive model was small. For the same indices, after allowing for age and smoking, the annual decline was greater in men whose trade had ever been a welder or caulker/burner compared with trades that did not involve these tasks. The proportion of variance explained by trade was on average half that due to smoking except when atopy was included in the analysis (see below); there was significant interaction between the two effects and between them and the effects of age. Neglecting the interactions the decline in $\mathrm{FEV}_{1}$ of a non-smoking, non-welder of mean age 50 was on average $16.2 \mathrm{ml} / \mathrm{y}$; the decline was increased by $16.4 \mathrm{ml} / \mathrm{y}$ if a welder and by $17.7 \mathrm{ml} / \mathrm{y}$ if a smoker or recent ex-smoker. Thus for a welder who smoked the average decline was $50.3 \mathrm{ml} / \mathrm{y}$, three times that of non-smoking other tradesmen. After allowing for age, the annual decline in $\mathrm{FEV}_{1}$ was also greater in men with respiratory symptoms than in those who were asymptomatic.

Table 6 Analyses in which atopy or IgE concentration $\left(I_{R} E\right.$ or $\left.I g E_{250}\right)$ contributed to the decline in lung function ( $\triangle F E V$, or $\triangle P E F$ ) in welders and caulker burners (WCB) but not other tradesmen

\begin{tabular}{|c|c|c|c|}
\hline \multicolumn{2}{|c|}{$\triangle F E V_{1}$} & \multicolumn{2}{|l|}{$\triangle P E F$} \\
\hline Units & Significant terms & Units & Significant terms \\
\hline $\begin{array}{c}\mathrm{ml} / \mathrm{y} \\
{ }_{0} / \mathrm{y}\end{array}$ & $\begin{array}{l}\text { Age, WCB, atopy } \\
\text { Age, WCB.IgE }{ }_{250}\end{array}$ & $\underset{\%}{\mathrm{ml} \mathrm{s}^{-1} \mathrm{y}^{-1}}$ & $\begin{array}{l}\text { Smoking } \\
\text { Smoking, WCB. IgE }\end{array}$ \\
\hline
\end{tabular}

In the welders and caulker/burners, but not the other tradesmen, atopic status or $\left[\mathrm{I}_{\mathrm{g}} \mathrm{E}\right]$ contributed to the description of the annual decline in lung function (table 6) but not to the risk of developing respiratory symptoms. The decline in $\mathrm{FEV}_{1}$ associated with atopic status and welding or caulker burning was on average $21 \mathrm{ml} / \mathrm{y}$. The interaction term between smoking and atopy or [IgE] was not significant except when [IgE] was replaced by $\log$ IgE; in this form a smaller proportion of the variance was explained.

Among the men in the 1980 subsample who were followed up, the mean total lung capacity did not change between the surveys; however, residual volume increased significantly and led to an increase in functional residual capacity despite a concurrent decrease in expiratory reserve volume. The latter change contributed to the reduction in vital capacity that was also due in part to a decrease in inspiratory capacity. The increase in residual volume a year was greater in smokers as defined than in non-smokers and long term ex-smokers, but there was no association with trade, atopy, or [IgE]. The transfer factor and $\mathrm{K}_{\mathrm{co}}$ on the two occasions separately were related to age, smoking category, and, in the case of transfer factor, to stature: however, there were no associations with trade, atopy, or [IgE] and this was also the case for the changes in $\mathrm{Tl}$ and $\mathrm{K}_{\mathrm{co}}$ over the period of follow up. The exercise ventilation $\left(\dot{V}_{\mathrm{E}} 45\right)$ at follow up was higher in smokers than non-smokers and the annual increase was related to age but again there were no associations with trade, atopy, or $\left[I_{8} E\right]$ : however, only relatively few data sets were available for the latter analysis (table 1).

\section{Discussion}

The validity of the conclusions depended on the measurements accurately representing the small changes in lung function that occurred over the period of follow up and on there being no material bias due to the subjects who were seen not being representative of those assessed initially. To avoid 
these sources of error the measurements were made by trained observers using the same or similar equipment and the same techniques, calibration procedures, and criteria for acceptability. No results were rejected because of a discrepancy between the initial and final values. The subjects who attended the laboratory had rather more reversible airflow obstruction on that occasion than when assessed at home but the differences were unrelated to trade so were unlikely to have influenced the conclusions. The interval between the surveys was optimal for investigating longitudinal changes. ${ }^{13}$ The model used for analysis allowed for the possibility that deterioration over the period of follow up was related to age and stature, while not introducing error from relating the changes to the initial values. ${ }^{10}$ Including the mean level of lung function in SD units as an independent variable increased the proportion of variance which was explained but somewhat reduced the effect attributed to fume exposure. This may have been due to the mean level itself being correlated with exposure to fumes. For this reason, despite its widespread use ${ }^{814}$ the mean level appeared not to be an appropriate independent variable when the aim was to investigate the long term effect of an environmental hazard.

The principal index of fume exposure was trade as a welder or caulker/burner compared with other trades except tack welders; the latter were excluded so as not to bias the result. ${ }^{15}$ The intensity of exposure up to 1979 and the intensity and duration of exposure during the period of follow up were also considered but did not contribute significantly. This was probably due to bias introduced by the men who remained at work being significantly younger, having fewer respiratory symptoms, and comprising significantly fewer smokers compared with the remainder. The redundancies and other factors in the shipyard contributed to the follow up extending over several years ${ }^{16}$ : however, changes on this account probably did not influence the result. Bias from lapses was also unimportant as the follow up rate among men who were alive at the time of follow up was $88 \%$ and the findings in 1979 for the men who were subsequently lapses did not differ materially from those who participated. Exposure to fumes did not appear to have contributed to the deaths between the surveys but the number of men who died was relatively small. Bias did occur in the composition of the subgroup of men on whom additional tests were carried out. In 1980 it was due to the selective inclusion of men who might have had emphysema or airflow obstruction. Emphysema turned out to be rare, but airflow obstruction was relatively common: it could have contributed to the longitudinal increase in residual volume in the subsample being materially larger than might have been expected from the cross sectional results. Bias at follow up was due to the men deciding for themselves whether or not to attend for additional tests. The difference in $\mathrm{FEV}_{1}$ between the participants and the non-attenders, however, was on average only $0.38 \mathrm{SD}$ units (approx $210 \mathrm{ml}$ ); this was too small to have been of much consequence.

The skin prick tests and measurement of $\mathrm{I}_{\mathrm{g}} \mathrm{E}$ were mostly only made at follow up, but where they were also available from 1980 the two sets of results were significantly correlated. Thus the use of the final rather than the mean IgE was unlikely to have introduced a material error. Changes in respiratory symptoms between the surveys were mainly associated with factors already identified during the initial cross sectional study, including age, smoking, previous pneumonia, and previous metal fume fever. The age related increase in prevalence of wheeze on most days, however, was larger when assessed longitudinally than cross sectionally. The reason for this was not clear. The association between development of symptoms and trade was significant in the case of grade of breathlessness but not the other symptoms. The association was independent of age, weight change, mean level of $\mathrm{FEV}_{1}$, and, in the subsample, ECG evidence for cardiac ischaemia; its persistence after taking into account so many other relevant variables raised the possibility that the development of breathlessness reflected a change in mental attitude. ${ }^{17}$ The contribution of coronary ischaemia to breathlessness was material (on average one clinical grade) and in line with other evidence. ${ }^{18}$

The relation of annual decline in lung function to age and smoking, and the significant interaction between these two effects, were consistent with those obtained in other longitudinal studies. ${ }^{19}$ The effect of trade was similar to and interacted with that of smoking. Thus older men who were both smokers and welders or burners had the steepest decline in lung function over the period of follow up. This result was obtained despite most of the men having been made redundant, so no longer exposed to fumes; thus the effect of the fumes persisted after exposure had ceased. The effect was still present after allowance had been made for the mean level of lung function over the period of follow up. The analysis of the subsample population suggested that possession of an atopic constitution predisposed to ongoing loss of lung function in welders: this interaction resembled that previously observed between smoking and atopy. ${ }^{2021}$ Both types of fume contain oxides of nitrogen and other irritant substances which might be expected to affect preferentially subjects with potentially labile airways. Alternatively, the interaction could have been due to some atopic welders and burners more readily being sensitised to fumes from burning paint or other surface coating material. In this event an association might have been expected between [IgE] and trade. No such association was observed but in support of the sensitisation hypo- 
thesis the contribution to decline in lung function of IgE concentration was greatest when the units used in the analysis gave weighting to the higher values. More information is needed on this subject.

In conclusion, the deleterious effects of trade as a welder or caulker/burner were related to age, atopy, and smoking, and mainly resulted from exposure for most or all of a working lifetime. The same deterioration would not necessarily affect men engaged after the introduction of exhaust ventilation and exposed only to generally low levels of welding fumes but other changes in the process could have a contrary effect. Currently the largest single step towards better respiratory health in shipyard workers would be the abandonment of smoking. A reduction in the incidence of pneumonia might also be beneficial though its achievement could entail additional investigations. The implications of having an atopic constitution needed to be explored further: the present results were on too limited a sample to justify including the absence of atopy among the selection criteria for new entrants to the shipbuilding industry.

The study was made possible through the collaboration of the subjects, the shop stewards, and the management of the shipyard. Mr C Elliott, Dr B King, Mrs V Posner, Dr J W Reed, Dr F S Rennie, Mrs A Stewart, and Miss J J Weller collected information for analysis; the Sunderland District Biochemistry Laboratory measured the serum IgE concentrations. The work was supported by a grant from the Health and Safety Executive. In addition, Dr J E Cotes and Dr D J Chinn were supported by the Medical Research Council and Dr B King by the European Coal and Steel Community. The University of Newcastle upon Tyne, Dr N P Keaney, and the Sunderland Health Authority kindly contributed facilities. Mrs M E Hyam and Mrs J Renwick prepared the manuscript.
1 Cotes JE, Feinmann EL, Male VJ, Rennie FS, Wickham CAC. Respiratory symptoms and impairment in shipyard welders and caulker/burners. Br J Ind Med 1989;46:292-301.

2 Medical Research Council. Questionnaire of respiratory symptoms. London: MRC, 1976.

3 Quanjer PH, ed. Standardised lung function testing. Bull Eur Physiopathol Respir 1983;19, suppl 5:1-98.

4 Blackburn H, Taylor HL, Okamoto N, Rautaharj P, Mitchell PL, Kirkhof AC. Standardisation of the exercise electrocardiogram. A systematic comparison of chest lead configurations employed for monitoring during exercise. In: Karvonen MJ, Barry AJ, eds. Physical activity and the heart: proceedings. Springfield, Illinois: Thomas, 1967:101-33.

5 Cotes JE. Lung function: assessment and application in medicine. 4th ed. Oxford: Blackwell, 1979.

6 Statistical package for the social sciences, user's guide. 2 nd ed. New York: McGraw-Hill, 1986.

7 Dixon WJ, ed. BMDP statistical software. Los Angeles: University of California Press, 1985.

8 Oldham PD. A note on the analysis of repeated measurements on the same subjects. J Chronic Dis 1962;15:969-77.

9 Cole TJ. Linear and proportional regression models in the prediction of ventilatory function. Journal of the Royal Statistical Society 1975;138:297-325.

10 Fletcher C, Peto R, Tinker C, Speizer FE. The natural history of chronic bronchitis and emphysema. Oxford: Oxford University Press, 1976:196-8.

11 Burrows B, Lebowitz MD, Camilli AE, Knudson RJ. Longitudinal changes in forced expiratory volume in one second in adults. Am Rev Respir Dis 1986;133:974-80.

12 Miller MR, Pincock AC. Predicted values: how should we use them? Thorax 1988;43:265-7.

13 Berry G. Longitudinal observations. Their usefulness and limitations with special reference to the forced expiratory volume. Bull Eur Physiopathol Respir 1974;10:643-56.

14 Kauffmann F, Drouet D, Lellouch J, Brille D. Twelve years spirometric changes among Paris area workers. Int J Epidemiol 1979;8:201-12.

15 Brisson C, Loomis D, Pearce N. Is social class standardisation appropriate in occupational studies? J Epidemiol Community Health 1987;41:290-4.

16 Cotes JE. Lessons from shipyards. (Milroy lecture.) $J R$ Coll Physicians 1988;22:232-6.

$17 \mathrm{King} \mathrm{B}$, Cotes JE. Relation of lung function and exercise capacity to mood and attitudes to health. Thorax 1989;44:402-9.

18 Wilhelmsen L, Wedel H, Tibbin G. Multivariate analysis of risk factors for coronary heart disease. Circulation 1973;48:950-8.

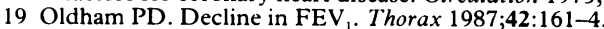

20 Burrows B, Lebowitz MD, Barbee RA. Respiratory disorders and allergy skin-test reactions. Ann Intern Med 1976;84: $134-9$.

21 Taylor RG, Joyce H, Cross E, Holland F, Pride NB. Bronchial reactivity to inhaled histamine and annual rate of decline in $\mathrm{FEV}_{1}$ in male smokers and ex-smokers. Thorax 1985;40:9-16.

Accepted 17 August 1989 